\title{
A Neural Network and Fuzzy Logic based MPPT Algorithm for Photovoltaic Pumping System
}

\author{
Salwa Assahout, Hayat Elaissaoui, Abdelghani El Ougli, Belkassem Tidhaf, Hafida Zrouri \\ Laboratory of Embedded Electronic Systems and Renewable Energy, University Mohammed First, National School of \\ Applied Sciences Oujda, Morocco
}

\begin{tabular}{|c|c|}
\hline Article Info & ABSTRACT \\
\hline & \multirow{10}{*}{$\begin{array}{l}\text { The use of solar energy had gained a great attention last decades, as it is } \\
\text { pollution-free. It is used in isolated areas for lighting, pumping, etc. } \\
\text { However, the extraction of the maximum power generated by a PVG at any } \\
\text { moment of the day is a big deal because the characteristic of a PVG in non- } \\
\text { linear which makes the location of the Maximum Power Point (MPP) } \\
\text { difficult. Therefore, a Maximum Power Point Tracking technique (MPPT) is } \\
\text { required to maximize the output power. In this paper, a photovoltaic water } \\
\text { pumping system has been studied. This system consists of three main parts: } \\
\text { PVG, a DC-DC boost converter and a DC motor coupled with a centrifugal } \\
\text { water pump. We have proposed a new MPPT algorithm based on Fuzzy logic } \\
\text { and Artificial Neural Network (ANN) to improve the system performances. } \\
\text { The ANN is used to predict the optimal voltage of the PVG, under different } \\
\text { environmental conditions (temperature and solar irradiance) and the fuzzy } \\
\text { controller is used to command the DC-DC boost converter. The proposed } \\
\text { method is compared to P\&O technic, by simulation under Matlab/Simulink, } \\
\text { to verify its effectiveness. }\end{array}$} \\
\hline Received Aug 27, 2018 & \\
\hline Revised Sep 12, 2018 & \\
\hline Accepted Sep 26, 2018 & \\
\hline Keyword: & \\
\hline $\begin{array}{l}\text { Artificial Neural Network } \\
\text { (ANN) }\end{array}$ & \\
\hline DC-DC boost converter & \\
\hline Fuzzy Logic & \\
\hline MPPT & \\
\hline Photovoltaic Generator (PVG) & \\
\hline
\end{tabular}

Copyright $@ 2018$ Institute of Advanced Engineering and Science. All rights reserved.

\section{Corresponding Author:}

Salwa Assahout, Laboratory of Embedded Electronic Systems and Renewable Energy. University of Mohammed First, National School of Applied Sciences Oujda, Morocco.

Email: 1snt1@ccu.edu.tw

\section{INTRODUCTION}

Water is one of the most vital natural resources for all life on earth. It is needed for drinking, domestic uses and it is required for large-scale irrigation [1] ; its availability and quality determines the quality of life of any country. Even though it is abundant, water has not always been available anywhere in the world. For that, water pumping systems in isolated areas should be considered as an emergency measure [2].

In order to pump the water to satisfy human needs, a source of power is needed, in that context, the use of solar energy is highly recommended $[3,4]$ because of two reasons; the first one is that these areas do not have access to the electricity grid and the installation of transmission lines and transformers is expensive, the second one is that the solar energy is inexhaustible and pollution-free [5].

A PVG converts light energy (solar irradiance) into electricity [6]. The electric power produced by a PVG to run a pumping water system depends on meteorological parameters variable in time [7]. The electrical characteristic of the panel is non-linear and has a particular point called "Maximum Power Point" (MPP) for which the panel operates at its maximum power, this point is sensitive to the climatic conditions (solar irradiance, and ambient temperature) [8] which makes the position of the MPP variable in time and therefore difficult to locate.

To extract the maximum power provided by a PVG whenever temperature or irradiation variation occurs , different maximum power point tracking (MPPT) techniques have been proposed [9], such as: Perturb 
and Observe (P\&O), Incremental Conductance (IC), Fuzzy Logic [10] and Artificial Neural Network (ANN) $[11,12]$.

In this paper, we are developing a new MPPT algorithm for a photovoltaic pumping system consisting of a DC-DC boost converter, whose purpose is to ensure matching between the source (PVG) and the load, generating an output voltage, which is higher than the input voltage, for a maximum power transfer. This algorithm combines ANN and fuzzy logic. the ANN aims to identify the optimal voltage $V_{M P P}$ corresponding to each value of temperature and irradiation based on the results of the training whereas the fuzzy controller gives the value of the converter duty cycle D.

\section{PHOTOVOLTAIC PUMPING SYSTEM}

The water pumping system considered in this work consists of a single PV module, a DC-DC boost converter, a MPPT algorithm and DC motor coupled with a centrifugal water pump [13].

\subsection{Modeling of Solar Panel}

The equivalent electric circuit of solar cell can be represented by a model of one diode [14] as shown in Figure 1.

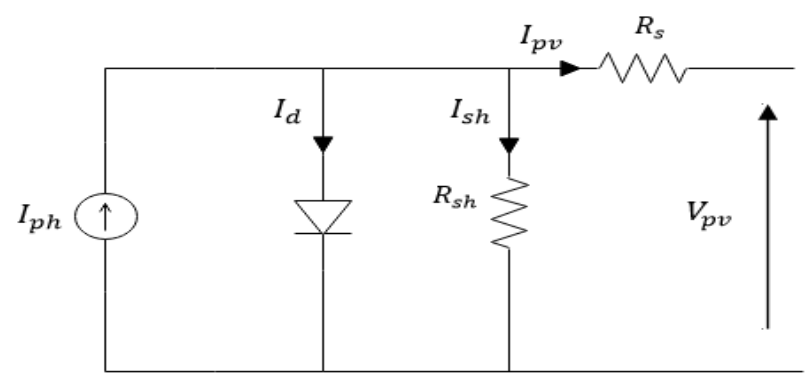

Figure 1. Equivalent circuit of a solar cell

$R_{S h}$ represents parallel resistance characterizing the leakage current at the surface of the cell due to the non- ideality of the P-N junction and impurities near the junction, $R_{S}$ series resistance presenting the different losses of connectors and currents.

$I_{d}$ and $I_{s h}$ are respectively diode current and shunt leakage current where $I_{P V}$ and $V_{P V}$ are respectively the current and the voltage of the cell.

The equation connecting the current delivered by a PV panel composed of $N_{s}$ ideal cells in series and the voltage at its terminals is given by:

$I_{P V}=N_{S}\left(I_{P h}-I_{0}\left(\exp \left(\left(\frac{V_{P V}+R_{S} I_{P V}}{N_{s} V_{t}}\right)-1\right)\right)\right.$

$-I_{p h}$ is photon generated current:

$I_{p h}=S I_{s c}$

$S$ is the irradiance $\left(\mathrm{W} / \mathrm{m}^{2}\right)$.

- $V_{t}$ is the thermal potential:

$V_{t}=\frac{n k T}{q}$

$n$ is the diode ideality factor $(n=1.62), k$ is the Boltzmann constant $(k=1.381 \mathrm{e}-23), T$ is the module temperature in Kelvin and $q$ is the electron charge ( $q=1.602 \mathrm{e}-19$ Coulomb).

$-I_{s c}$ is the short current:

$$
I_{s c}=I_{s c_{-} r e f}\left[1+\left(a\left(T-T_{r e f}\right)\right)\right]
$$


$I_{s c_{-} r e f}$ is the short circuit current per cell, $a$ is the temperature coefficient of $I_{s c}$ and $T_{r e f}$ is the reference temperature in Kelvin $\left(T_{r e f}=298 \mathrm{~K}\right)$.

- $I_{0}$ is the reverse saturation current:

$$
I_{0}=I_{r s}\left(\frac{T}{T_{\text {ref }}}\right)^{\frac{3}{n}} \exp \left(\frac{E_{g} q}{n k}\left(\frac{1}{T_{\text {ref }}}-\frac{1}{T}\right)\right)
$$

Where $E_{g}$ is the band gap energy.

$-I_{r s}$ is the reverse saturation current for $T_{r e f}=298 \mathrm{~K}$ :

$$
I_{r s}=\frac{I_{S c_{\_} r e f}}{\exp \left(\frac{V_{\text {oc_ref }}}{V_{t \_r e f}}\right)-1}
$$

$V_{\text {oc_ref }}$ is the open circuit voltage per cell, $V_{t \_r e f}$ is the thermal potential for $T_{r e f}$. In our study, we consider the TE500CR panel; its characteristics are shown in Table 1.

Table 1. Characteristics of the TE500CR Panel

\begin{tabular}{cc}
\hline Rated Power $\left[P_{M P P}\right]$ & $65[\mathrm{Wp}]$ \\
\hline Rated Voltage $\left[V_{M P P}\right]$ & $18[\mathrm{~V}]$ \\
Rated Current $\left[I_{M P P}\right]$ & $3.6[\mathrm{~A}]$ \\
Open Circuit Voltage $\left[V_{O C}\right]$ & $22.3[\mathrm{~V}]$ \\
Short Circuit Current $\left[I_{O C}\right]$ & $3.9[\mathrm{~A}]$ \\
Number of cells: $N_{S}$ & 36 \\
\hline
\end{tabular}

The (V-I) and (V-P) characteristics of the TE500CR panel, under different values of temperature and solar irradiance, are shown respectively in Figure 2(a) and Figure 2(b), Figure 3(a) and Figure 3(b).

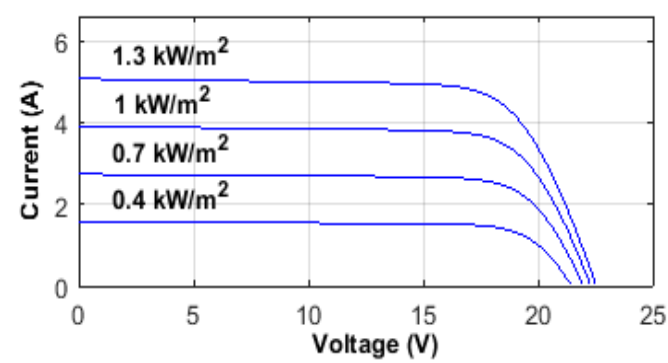

(a)

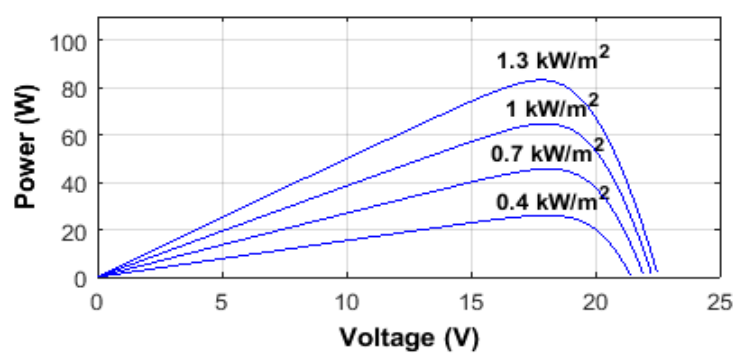

(b)

Figure 2. (V-I) characteristic (a) and (V-P) characteristic (b) of the TE500CR panel at $\mathrm{T}=25^{\circ} \mathrm{C}$

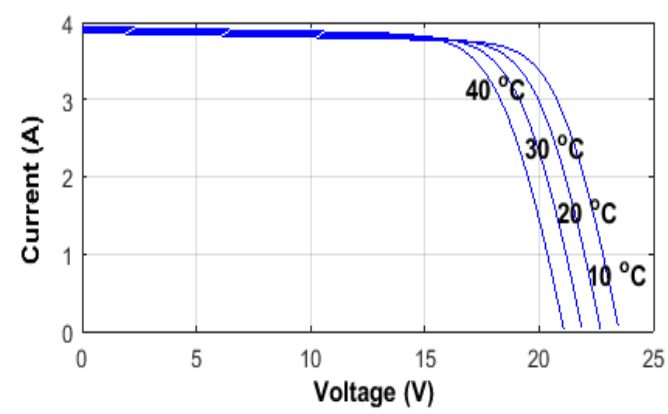

(a)

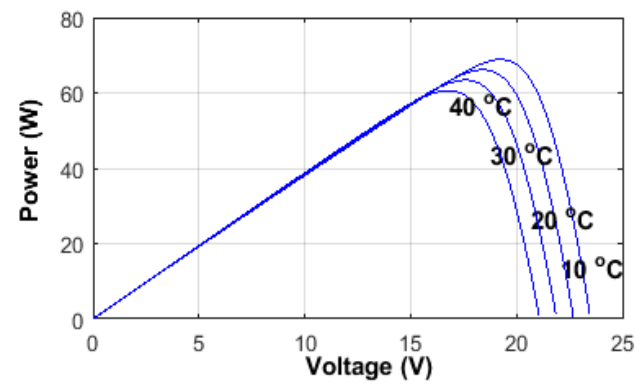

(b)

Figure 3. (V-I) characteristic (a) and (V-P) characteristic (b) of the TE500CR panel at $\mathrm{S}=1000 \mathrm{~W} / \mathrm{m}^{2}$ 


\subsection{Modeling of the Pumping System}

A photovoltaic water pumping system consists of:

- Photovoltaic Genarator : which generates the electrical power.

- a DC-DC boost converter: which converts a DC voltage in another higher DC voltage.

- a DC motor: which converts electrical energy into mechanical energy to turn the pump.

- a centrifugal pump model: its role is pumping water by circulating it in a rotating wheel.

- The equivalent circuit of the system is presented in Figure 4 [15]:

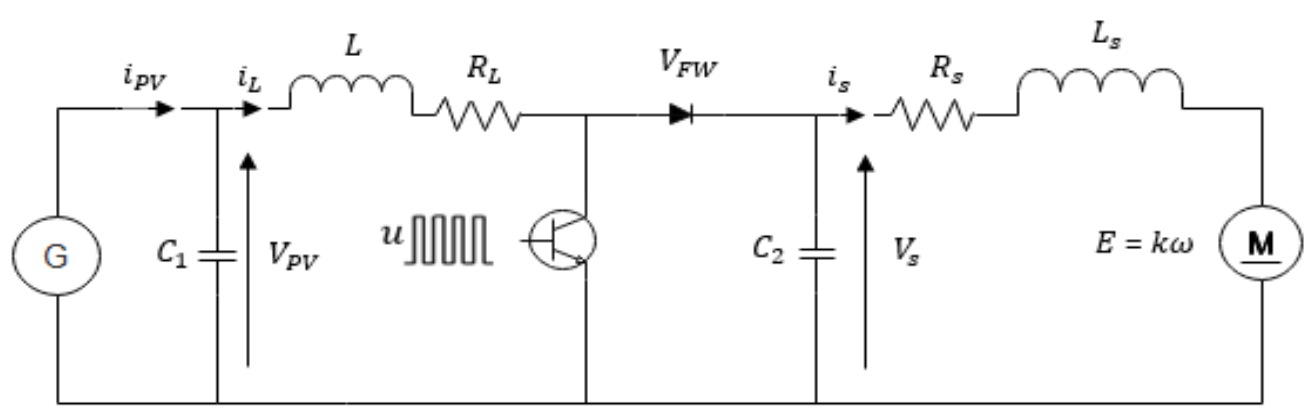

Figure 4. Equivalent circuit of the photovoltaic water pumping system

The system is governed by the following equations:

$$
\begin{aligned}
& \frac{d i_{L}}{d t}=\frac{V_{P V}}{L}-\frac{R_{L}}{L} i_{L}+\frac{-R_{m} i_{L}+V_{F W}+V_{S}}{L} u-\frac{V_{F W}}{L}-\frac{V_{S}}{L} \\
& \frac{d V_{P V}}{d t}=\frac{i_{P V}}{C_{1}}-\frac{i_{L}}{C_{1}} \\
& \frac{d i_{S}}{d t}=\frac{-R_{S}}{L_{S}} i_{S}+\frac{V_{S}}{L_{S}}-\frac{k}{L_{S}} \omega \\
& \frac{d V_{S}}{d t}=-\frac{i_{S}}{C_{2}}+\frac{i_{L}}{C_{2}}-\frac{i_{L}}{C_{2}} u \\
& \frac{d \omega}{d t}=\frac{k}{J_{M}} i_{S}-\frac{B_{M}}{J_{M}} \omega-\frac{T_{L}}{J_{M}}
\end{aligned}
$$

where; $V_{S}, i_{s}, R_{s}$ and $L_{s}$ are respectively the motor's armature voltage, current, resistance and inductance.

$k, J_{M}, B_{M}, T_{L}$ and $\omega$ are respectively the motor's torque constant, rotor moment of inertia, frictional coefficient, load torque and angular velocity of the motor.

$L, R_{L}$ and $i_{L}$ are respectively the self-inductance, resistance and current.

$C_{1}$ and $C_{2}$ are respectively the input and the output capacitance.

$u, V_{F W}, R_{m}$ are respectively the control input, diode forward voltage and the resistance characterizing the lost through the IGBT.

From the system below, we get the following state representation:

$$
\dot{x}=\mathrm{A} x+b u+d
$$

where;

$$
\mathbf{A}=\left[\begin{array}{ccccc}
\frac{-R_{L}}{L} & \frac{1}{L} & 0 & \frac{-1}{L} & 0 \\
\frac{-1}{C_{1}} & 0 & 0 & 0 & 0 \\
0 & 0 & \frac{-R_{s}}{L_{s}} & \frac{1}{L_{s}} & \frac{-k}{L_{s}} \\
\frac{1}{C_{2}} & 0 & \frac{-1}{C_{2}} & 0 & 0 \\
0 & 0 & \frac{k}{J_{s}} & 0 & \frac{-B_{s t}}{J_{M}}
\end{array}\right] \mathbf{b}=\left[\begin{array}{c}
\frac{-R_{m} i_{L}+V_{P W}+V_{s}}{L} \\
0 \\
0 \\
\frac{-i_{L}}{C_{2}} \\
0
\end{array}\right] \mathrm{d}=\left[\begin{array}{c}
\frac{-V_{P W}}{L} \\
\frac{i_{P V}}{C_{1}} \\
0 \\
0 \\
\frac{-T_{L}}{J_{M}}
\end{array}\right] x=\left[\begin{array}{c}
i_{L} \\
V_{P V} \\
i_{s} \\
V_{s} \\
\omega
\end{array}\right]
$$




\section{MPPT CONTROLLER}

In our study, we have compared two MPPT algorithms: one is based on P\&O and the other on ANN. $\mathrm{P} \& \mathrm{O}$ and $\mathrm{ANN}$ are used for the identification of $\left(V_{M P P}\right)$, while the fuzzy controller is used in both algorithms to determine the duty cycle (D).

\subsection{Perturb and Observe $(\mathbf{P \& O})$}

Perturb and observe $(\mathrm{P} \& \mathrm{O})$ maximum power point tracking algorithm [16] is the most commonly used method due to its ease of implementation. The principle of this operation is presented in Figure 5.

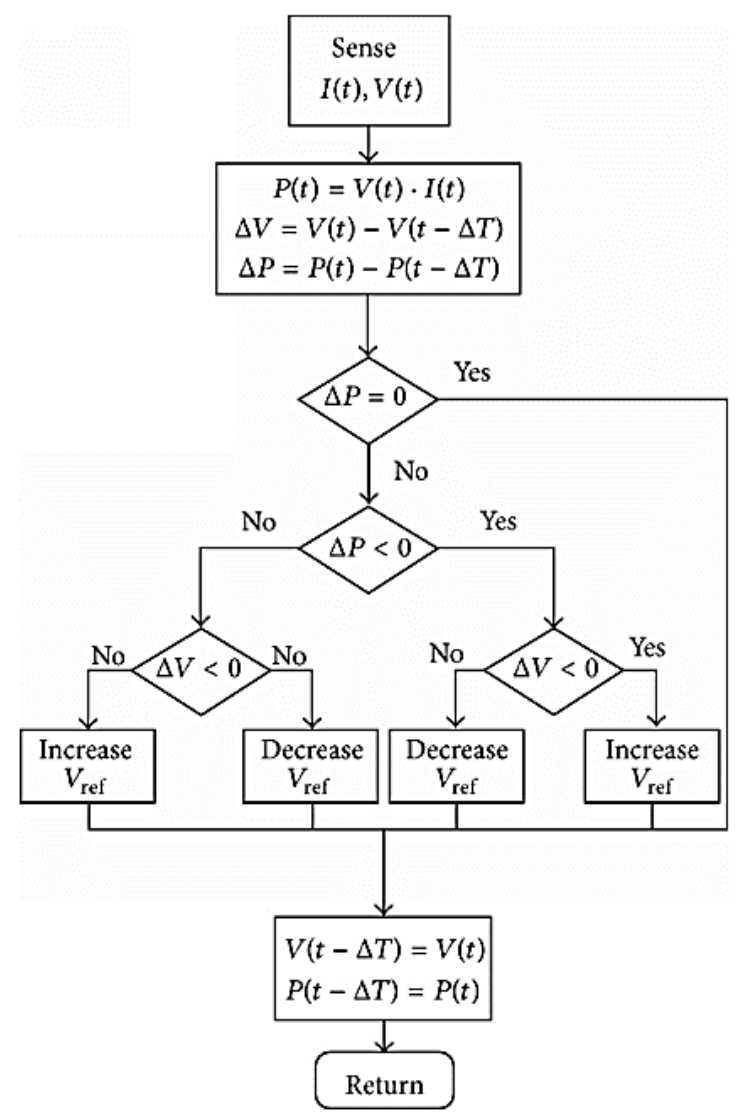

Figure 5. Perturb and Observe Algorithm (P\&O)

\subsection{Neural Netwrok based MPPT}

An artificial neuron as shown in Figure 6 is a mathematical function that tries to emulate the behavior of a biological neuron [17]. It receives a variable number of inputs, which are the external inputs or outputs of the other neurons and generates a unique output. Its processing consists in assigning to its output $Y_{k}$ the result of an activation function. The complete operation is described as follows:

$Y_{k}=\Phi\left(f\left(W_{k p}, X_{p}\right)+\theta_{k}\right)$

where; $X_{p}$ : are the inputs of the system.

$W_{k p}$ : are synaptic weights, their values represent the interaction between the presynaptic $p^{\text {th }}$ neuron and the postsynaptic $k^{\text {th }}$ neuron.

$\theta_{k}$ : is the bias or threshold.

$f:$ is the propagation rule, the most common used is a linear function.

$\Phi:$ is the activation function, it gives the output of the neuron.

$Y_{k}:$ is the output of the system. 


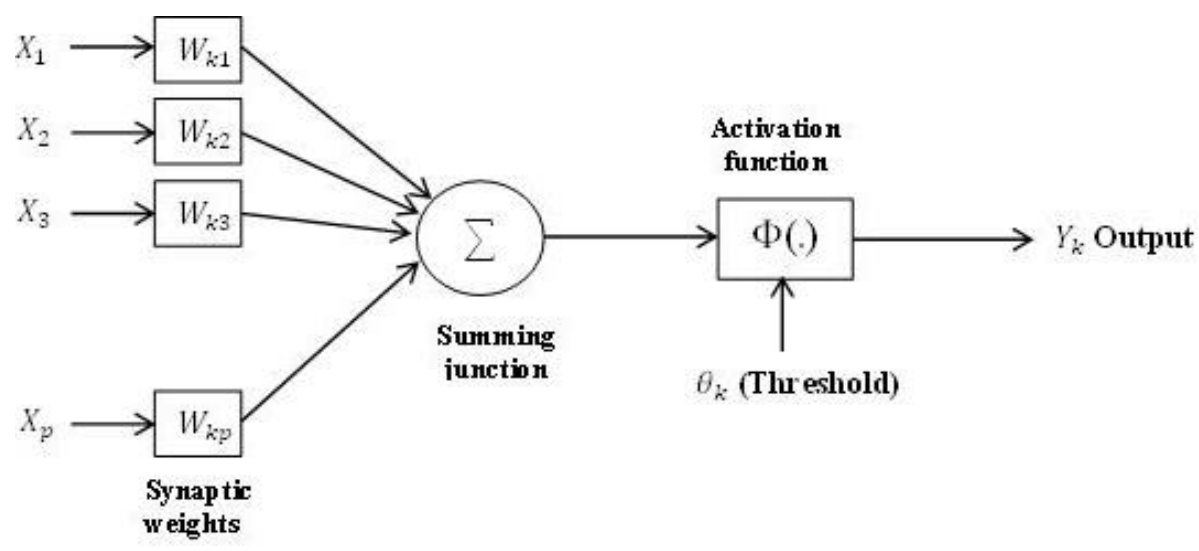

Figure 6. Representation of an artificial neuron

In our case, the proposed ANN aims to predict the PVG optimal voltage $\left(V_{M P P}\right)$ at any given cell temperature $(\mathrm{T})$ and solar irradiation $(\mathrm{S})$ based on the training results of a dataset containing the $V_{M P P}$ associated to each couple (T, S). We have used a Multilayer Perceptron, which is a class of feedforward networks [18]. We have chosen a single hidden layer to not complicate the system. So, we have used three layers of nodes as shown in Figure 7.

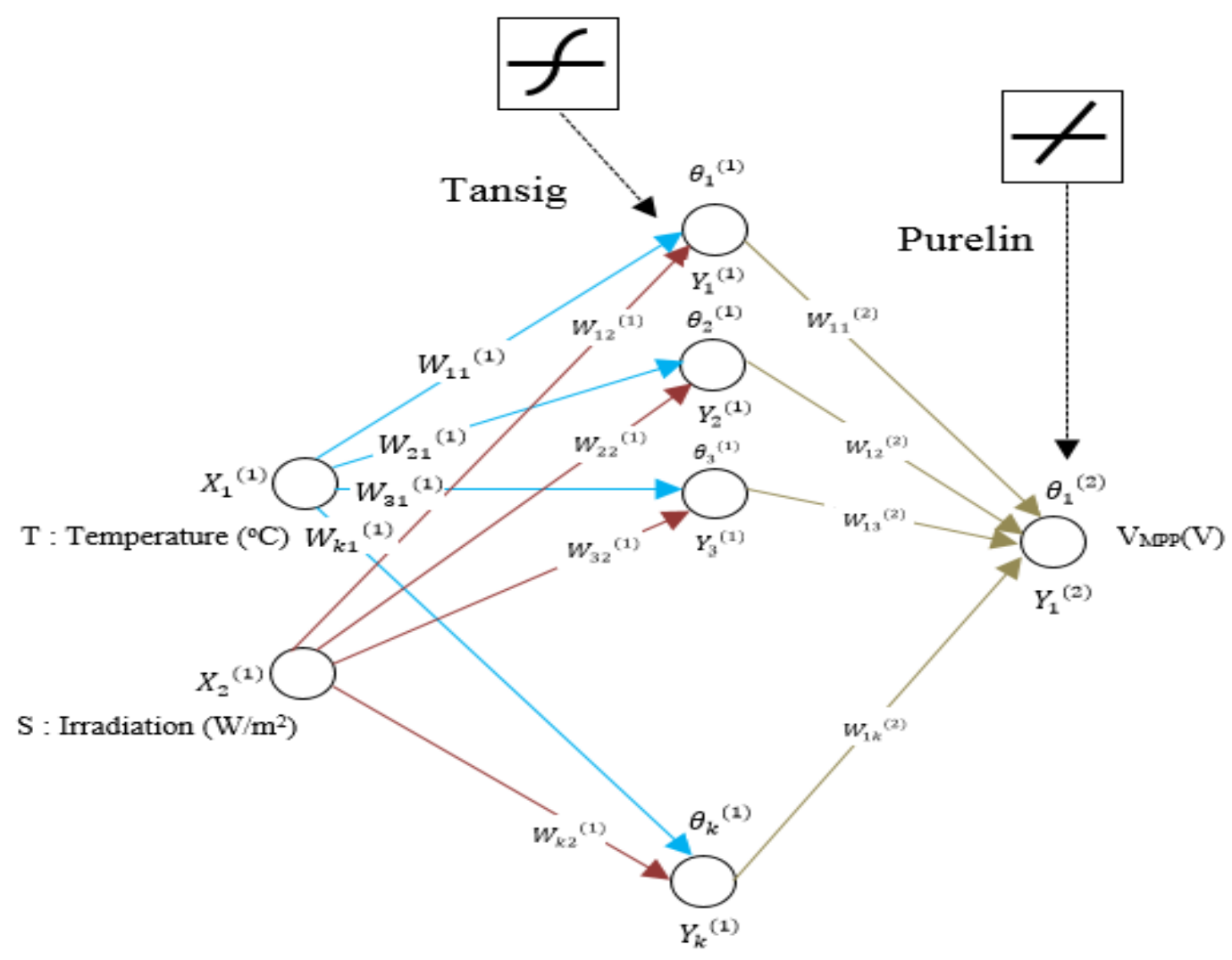

Figure 7. Prediction of $V_{M P P}$ using an ANN

- The first layer: it contains inputs $(\mathrm{T}, \mathrm{S})$.

- The second layer: it is called the hidden layer, the outputs of the previous layer serve as inputs of that layer. A sigmoid activation function (tansig) is used. 
- The third layer: the information of the previous layer is processed and the output is generated by using a linear function (purelin).

where; $X_{1}{ }^{(1)}$ and $X_{2}{ }^{(1)}$ are the inputs : temperature (T) and irradiation (S).

$Y_{1}^{(2)}$ is the output: optimal voltage $\left(V_{M P P}\right)$

The outputs of each layer are calculated as follow:

$$
\begin{aligned}
& Y_{k}{ }^{(1)}=\operatorname{tansig}\left(\sum_{p=1}^{2} W_{k p}{ }^{(1)} X_{p}{ }^{(1)}+\theta_{k}{ }^{(1)}\right) \\
& Y_{1}^{(2)}=\operatorname{purelin}\left(\sum_{p=1}^{k} W_{1 p}{ }^{(2)} Y_{p}{ }^{(1)}+\theta_{1}{ }^{(2)}\right)
\end{aligned}
$$

The database contain inputs and outputs as well, so we have used a supervised learning algorithm with backpropagation. The Levenberg Marquardt training algorithm (LM) trains the network [19]. We have changed the number of neurons in the hidden layer until the regression coefficient R-square $\left(R^{2}\right)$ gets closest to 1 .

\subsection{Fuzzy Controller}

A fuzzy controller is used due to its ease to implement; it does not required a mathematical model of the system. The fuzzy controller is used for the command of the system, its role is to estimate the value of the duty cycle $\mathrm{D}$ based on values of the error $(\mathrm{E})$ and the change of that error (DE). Where $\mathrm{E}$ is the difference between the predicted voltage by ANN (output of the ANN) and the output voltage of the converter. The fuzzy controller contains three main parts $[20,21]$ :

a. Fuzzification: Transformation of a numerical value into a degree of fuzziness by evaluation of a membership function.

b. Inference: this step aims to link the fuzzy input and output variables through rules which are expressed as follow: If $E$ is $A_{1}$ and $D E$ is $A_{2}$ Then $D$ is $\mathrm{B}$. Where $E, D E$ and $D$ are the characteristic physical quantities of the system. $A_{1}, A_{2}$ and $\mathrm{B}$ are the linguistic terms. In our case, five levels are used: NB (negative big), NS (negative small), ZE (zero), PS (positive small) and PB (positive big). In this paper Mamdani's fuzzy inference method, with Max-Min operation fuzzy combination has been used. The control rules of the fuzzy controller are indicated in Table 2.

Table 2. Rules base of Fuzzy Controller

\begin{tabular}{cccccc}
\hline NE & NB & NS & ZE & PS & PB \\
\hline NS & ZE & ZE & PB & PB & PB \\
ZE & PS & ZE & ZE & ZE & NS \\
PS & NS & NS & NS & ZE & ZE \\
PB & NS & NB & NB & ZE & ZE \\
\hline
\end{tabular}

3-Defuzzification: Transformation of a fuzzy set of an output linguistic variable into a numeric value. We have used the method of determination of the center of gravity (COA) of the final combined fuzzy set. The process of the fuzzy controller is shown in Figure 8. The membership functions of E, DE and D are shown respectively in Figure 9(a), Figure 9(b) and Figure 9(c).

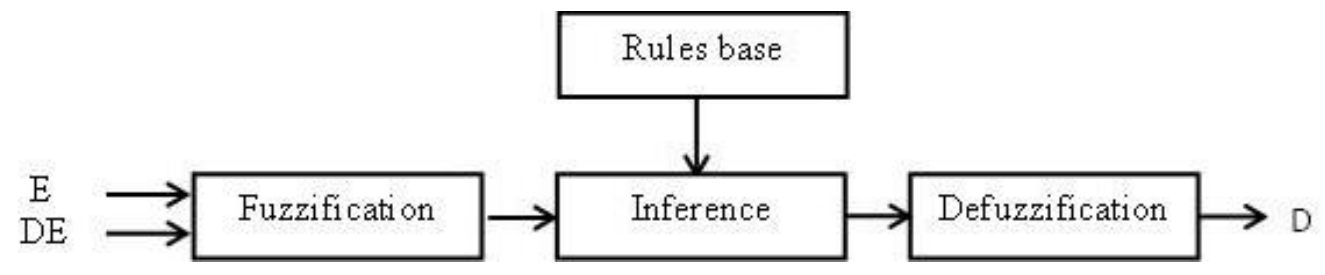

Figure 8. Structure of fuzzy controller 


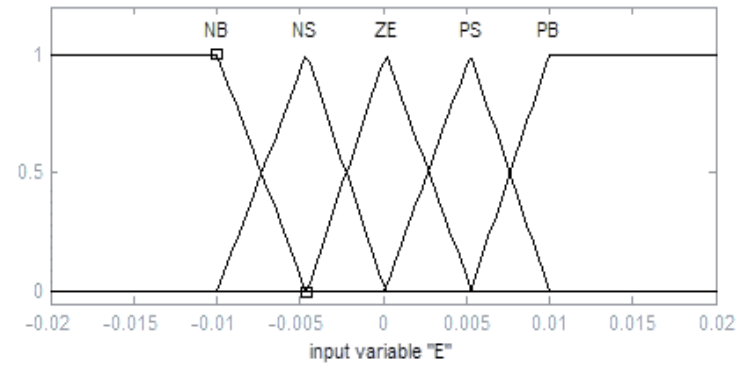

(a)

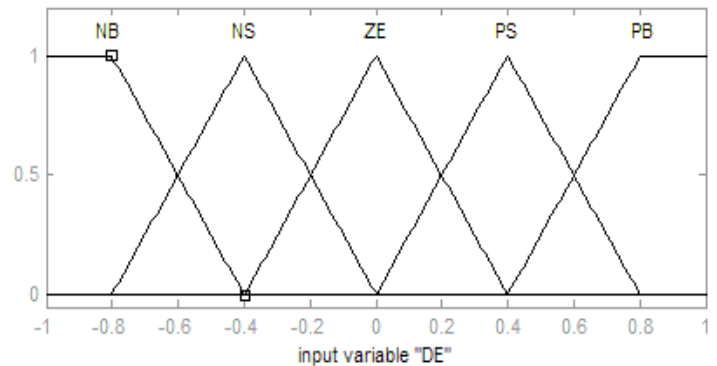

(b)

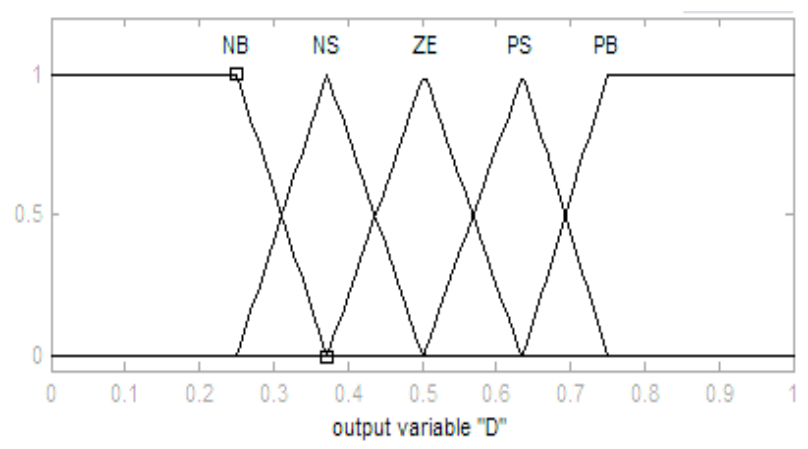

(c)

Figure 9. Membership functions of the error (a) - change of error (b) - duty cycle (c)

\section{SIMULATION AND RESULTS}

In order to evaluate the performance of the ANN and fuzzy logic based MPPT algorithm, a simulation under Matlab/Simulink was conducted. The Simulink model is shown in Figure 10.

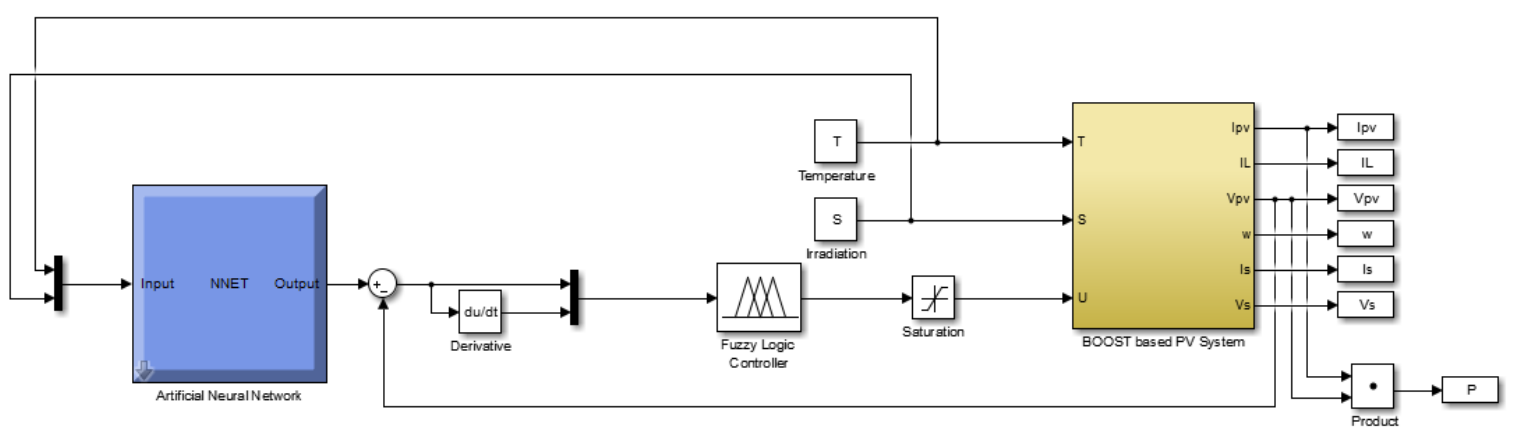

Figure 10. ANN and fuzzy logic based MPPT algorithm implementation on Simulink

Simulation results of the motor's speed, converter's duty cycle, instantaneous PV power and PV output voltage for the $\mathrm{P} \& \mathrm{O}$ based MPPT and ANN based MPPT, at standard conditions $\left(\mathrm{T}=25^{\circ} \mathrm{C}\right.$, $\mathrm{S}=1000 \mathrm{~W} / \mathrm{m}^{2}$ ), are shown respectively in Figure 11(a), Figure 11(b), Figure 11(c) and Figure 11(d).

In Figure 11 (a), the variation of the motor speed is shown. Comparing with the P\&O algorithm, the proposed algorithm gives better performances: the response time is reduced, the system gets stable and reaches a higher final value after a few oscillations. In Figure 11 (b), the variation of the duty cycle is shown. With the proposed algorithm, the system has better stability, which is the most important performance. In Figure 11 (c), the variation of instantaneous power is shown. The proposed algorithm allows increasing the final value and minimizing the oscillations and time response. The variation of PV output voltage is shown in Figure 11 (d). In a similar way to the power, the proposed algorithm brings the system to a higher final value in a few time and without oscillations. Figure 12(a) and Figure 12(b) present respectively the climatic conditions during a whole day (solar irradiance and temperature). 


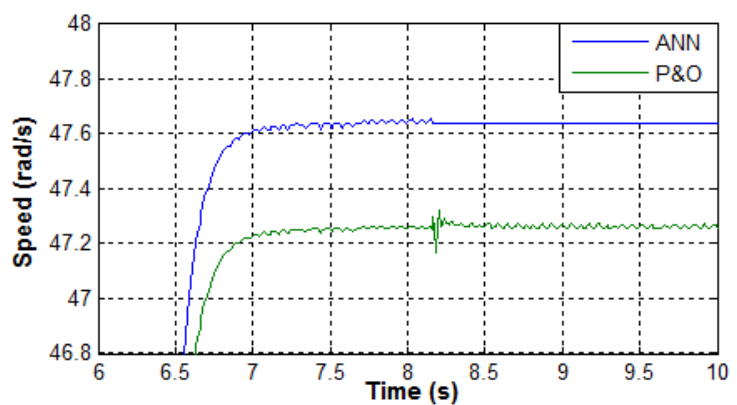

(a)

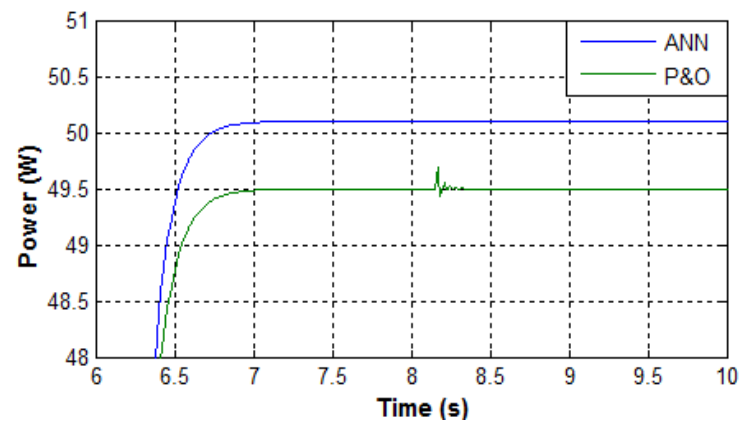

(c)

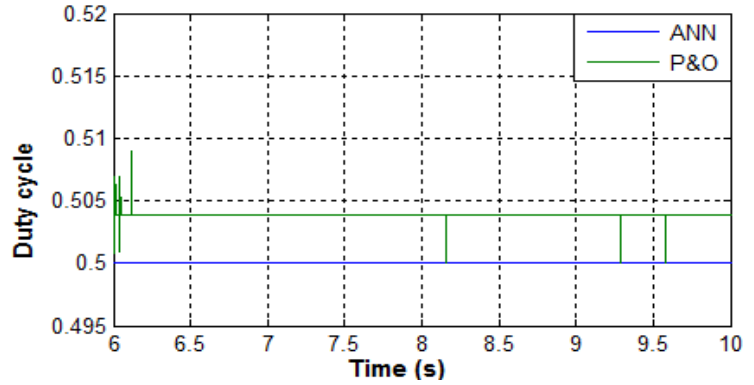

(b)

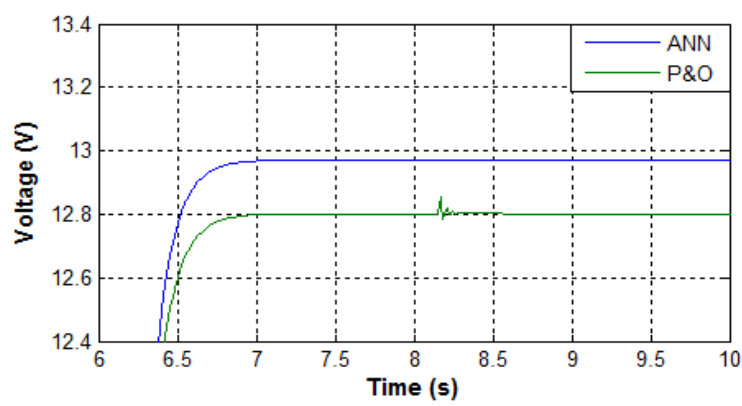

(d)

Figure 11. Variation of motor's speed (a), converter's duty cycle (b), instantaneous PV power (c) and PV output voltage $(\mathrm{d})$ at standard conditions $\left(\mathrm{T}=25^{\circ} \mathrm{C}, \mathrm{S}=1000 \mathrm{~W} / \mathrm{m}^{2}\right)$

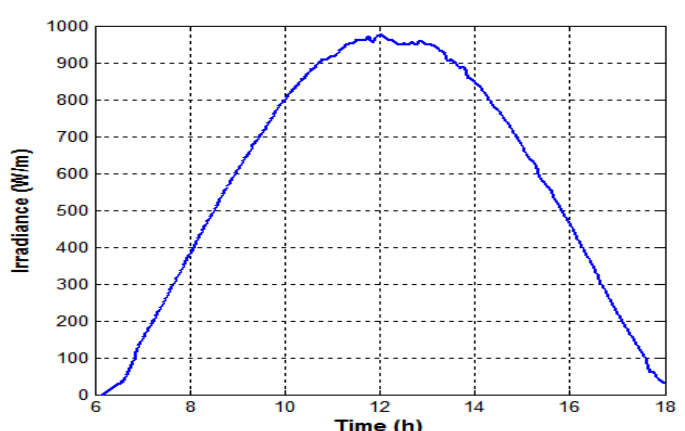

(a)

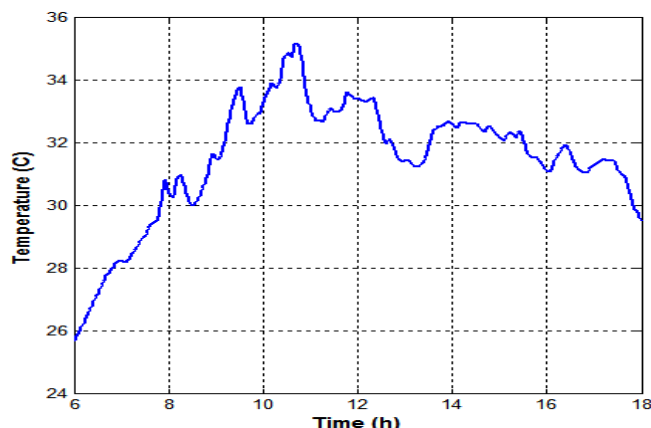

(b)

Figure 12. Solar irradiance (a) and temperature (b) during a whole day

Simulation results of the motor's speed, converter's duty cycle, instantaneous PV power and PV output voltage for the P\&O based MPPT and ANN based MPPT, during a day, are shown respectively in Figure 13(a), Figure 13(b), Figure 13(c) and Figure 13(d).

Accordring to the simulation results, the use of ANN and fuzzy logic improves the system performances. The proposed algorithm gives a better stability and accuracy to the system. As it is seen in Figure 13(a), Figure 13(b), Figure 13(c) and Figure 13(d), the curves represent a few oscillations and reach a higher final value comparing to the P\&O based MPPT. 


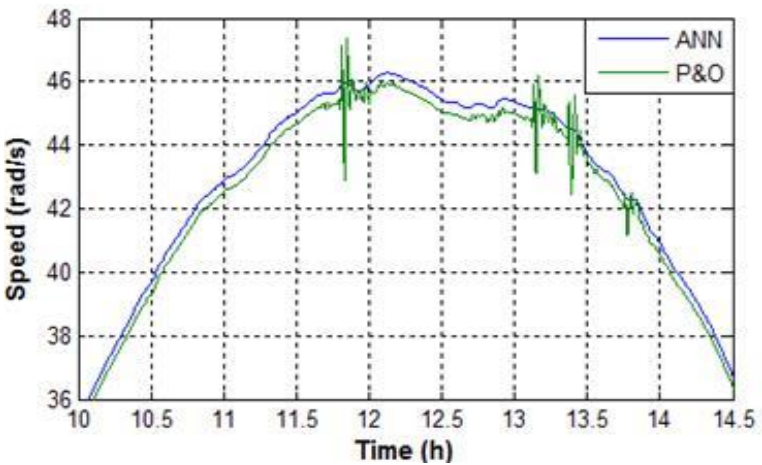

(a)

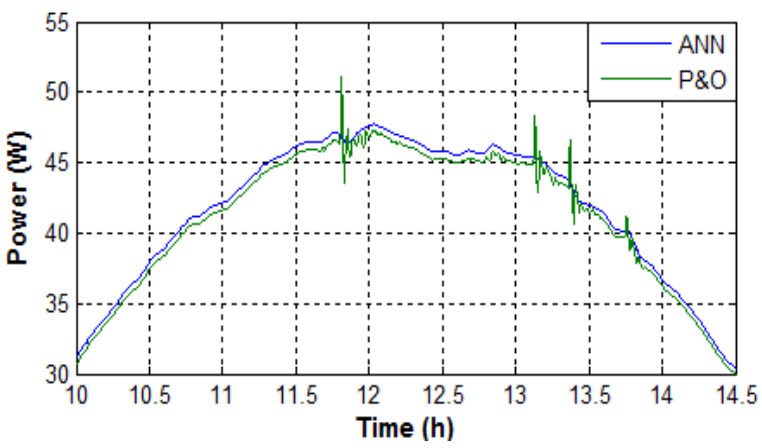

(c)

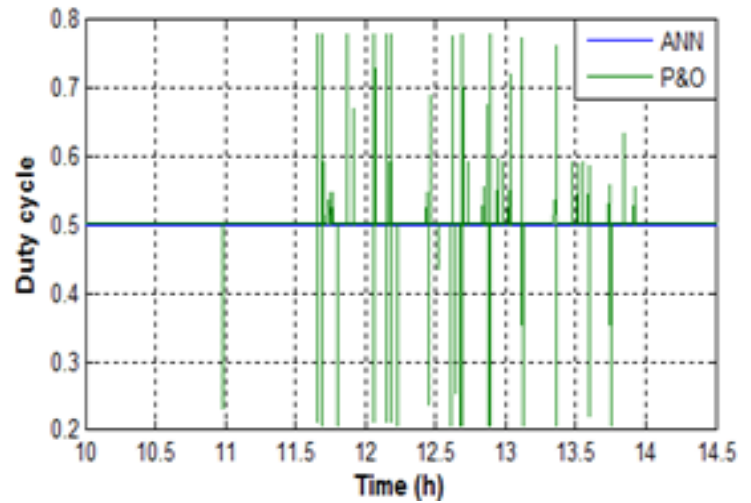

(b)

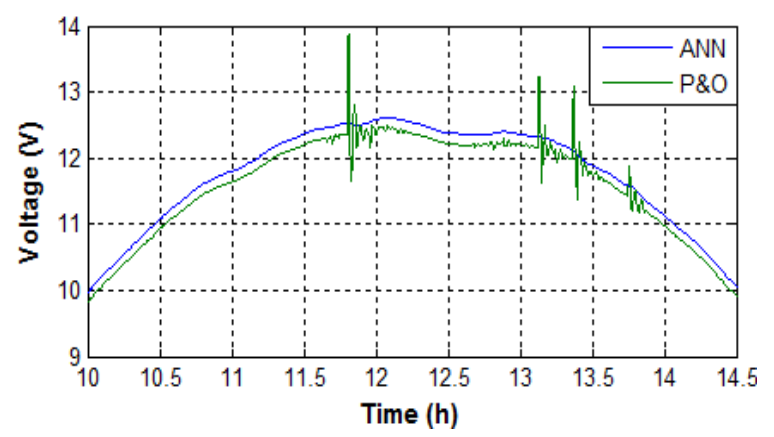

(d)

Figure 13. Variation of motor's speed (a), converter's duty cycle (b), instantaneous PV power (c) and PV output voltage $(\mathrm{d})$ during a day

\section{CONCLUSION}

In this paper, an ANN and Fuzzy Logic based Maximum power tracker for photovoltaic pumping system has been proposed and compared with a P\&O and Fuzzy Logic based MPPT.

The ANN and $\mathrm{P} \& \mathrm{O}$ are used for the identification the optimal voltage $\left(V_{M P P}\right)$ whereas the fuzzy controller is used to determine the duty cycle (D) of the DC-DC boost converter. Those MPPT algorithms had been tested by simulation under Matlab/Simulink.

According to the simulation results, it is clear that a MPPT based on ANN and Fuzzy Logic is more efficient. This algorithm has proven that it gives better performances: the response time is fast, the system is more accurate and robust to changing weather conditions.

\section{REFERENCES}

[1] Saccon P. Water for agriculture, irrigation management. Appl Soil Ecol. 2018; 123: 793-796.

[2] Meah K, Fletcher S, Ula S. Solar photovoltaic water pumping for remote locations. Renew Sustain Energy Rev. 2008; 12(2): 472-487.

[3] Aliyu M, Hassan G, Said SA, Siddiqui MU, Alawami AT, Elamin IM. A review of solar-powered water pumping systems. Renew Sustain Energy Rev. 2018; 87: 61-76.

[4] Sontake VC, Kalamkar VR. Solar photovoltaic water pumping system - A comprehensive review. Renew Sustain Energy Rev. 2016; 59: 1038-1067.

[5] Letcher Trevor M. Why Solar Energy? A Compr Guid to Sol Energy Syst. 2018: 3-16.

[6] Kumari JS, Sai Babu C, Professor A. Mathematical Modeling and Simulation of Photovoltaic Cell using MatlabSimulink Environment. Int J Electr Comput Eng (IJECE). 2012; 2(1): 2088-8708.

[7] Tiwari AK, Kalamkar VR. Effects of total head and solar radiation on the performance of solar water pumping system. Renew Energy. 2018; 118: 919-927.

[8] Dorahaki S. Evaluating the radiation and temperature effect on photovoltaic systems. Bull Electr Eng Informatics. 2015; 4(1): 1-6.

[9] Abdourraziq MA, Maaroufi M, Info A. Experimental Verification of the Main MPPT Techniques for Photovoltaic System. International Journal of Power Electronics and Drive Systems (IJPEDS). 2017; 8(1): 384-391. 
[10] Miqoi S, El Ougli A, Tidhaf B, Rabhi A. Application of fuzzy logic on a PV water pumping system. $3^{\text {rd }}$ International Symposium on Environment Friendly Energies and Applications. 2014.

[11] Yaichi M, Fellah M, Mammeri A. A Neural Network Based MPPT Technique Controller for Photovoltaic Pumping System. International Journal of Power Electronics and Drive System (IJPEDS). 2014; 4(2): 241-255.

[12] Elobaid LM, Abdelsalam AK, Zakzouk EE. Artificial neural network-based photovoltaic maximum power point tracking techniques: a survey. IET Renew Power Gener. 2015; 9(8): 1043-1063.

[13] Ouachani I. Optimization and Control for a Photovoltaic Pumping System. Second International Conference on Renewable Energy Research and Applications. 2013: 20-23.

[14] Bikaneria J, Prakash Joshi S, Joshi A, Service Manager A, trucking K. Modeling and Simulation of PV Cell using One-diode model. Int J Sci Res Publ. 2013; 3(10): 2250-3153.

[15] Miqoi S, El Ougli A, Boutouba M, Tidhaf B, Rabhi A. Fuzzy sliding mode control for maximum power point tracking of a photovoltaic pumping system. Journal of Electrical Systems. 2017; 13-1(1017): 95-114.

[16] Ahmed J, Salam Z. An improved perturb and observe (P\&O) maximum power point tracking (MPPT) algorithm for higher efficiency. Appl Energy. 2015; 150: 97-108.

[17] Guresen E, Kayakutlu G. Definition of Artificial Neural Networks with comparison to other networks. Procedia Comput Sci. 2011; 3: 426-433.

[18] Hristev R. The ANN Book. 1998.

[19] Yu H, Wilamowski B. Levenberg-Marquardt Training. 2011: 1-16.

[20] Al-Majidi SD, Abbod MF, Al-Raweshidy HS. A novel maximum power point tracking technique based on fuzzy logic for photovoltaic systems. Int J Hydrogen Energy. 2018.

[21] Samosir AS, Gusmedi H, Purwiyanti S, Komalasari E. Modeling and Simulation of Fuzzy Logic based Maximum Power Point Tracking (MPPT) for PV Application. Int J Electr Comput Eng (IJECE). 2018; 8(3): 1315-1323. 